\title{
Kübital tünel sendromu ve ulnar sinirin diğer tuzak nöropatileri
}

\section{Cubital tunnel syndrome and other ulnar nerve compression neuropathies}

\author{
Mehmet Şükrü Şahin ${ }^{1}$, Süleyman Altun², Barış Kafa ${ }^{3}$ \\ ${ }^{1}$ Başkent Üniversitesi Tıp Fakültesi, Ortopedi ve Travmatoloji Anabilim Dalı, Antalya \\ ${ }^{2}$ Dr. Sadi Konuk Eğitim ve Araştırma Hastanesi, Bakırköy, İstanbul \\ ${ }^{3}$ Atatürk Eğitim ve Araştırma Hastanesi, Ankara
}

\begin{abstract}
Ulnar sinir tuzak nöropatisi, karpal tünel sendromundan sonra en sık görülen tuzak nöropatidir. Anatomik lokalizasyonu nedeniyle, en sık dirsek bölgesinde tuzaklanır; ikinci en sık bölge ise el bileği seviyesidir. Dirsek bölgesindeki potansiyel tuzaklanma bölgeleri, Struthers arkadı, mediyal intermusküler septum, retroepikondiller oluk, kübital tünel (humeroulnar arkad) ve fleksör pronator aponöroz olup, en sık kübital tünel ve retroepikondiller olukta tuzaklanmaktadır. El bileği hizasında sıkışma seviyesine göre bulgular, saf motor, saf duyu veya mikst formda olabilmektedir. Guyon kanalı, ulnar sinirin el bileği bölgesinde sıkışma alanlarından biridir. Guyon kanalındaki sıkışmanın en önemli nedeni, yer kaplayan lezyonlardır. Tanısı, hastanın şikayetleri ile birlikte fizik muayene ile, elektrodiyagnostik ve radyolojik incelemelerle gerçekleştirilir. Tedavide, konservatif ve cerrahi seçenekler bulunmaktadır. Konservatif tedaviye cevap vermeyen olgularda, cerrahi tedavi yapılır. Kübital tünel sendromu cerrahi tedavisinde kullanılan yöntemlerin tamamında, yeterli fonksiyonel sonuçlar elde edilebilmektedir. El bileği seviyesindeki tuzaklanmalarda ise, nedene yönelik iyi sonuçlar alınabilmektedir. Bu derlemede, ulnar sinirin tuzaklanma bölgelerinden kübital tünelde ve el bileğinde oluşan nöropatinin patofizyolojisini, klinik ve elektrofizyolojik tanısını ele aldıktan sonra, cerrahi tedavi seçenekleri ve sonuçları tartışılacaktır.
\end{abstract}

Anahtar sözcükler: ulnar sinir; tuzak nöropatisi; kübital tünel sendromu; dekompresyon
Compression neuropathy of ulnar nerve is the most frequent entrapment neuropathy after carpal tunnel syndrome. Because of its anatomic localization, it is mostly trapped in elbow and secondly the wrist. Even though it is mostly compressed in cubital tunnel and retroepicondylar groove in the elbow; other possible regions where trapping may occur are arcade of Struthers, medial intermuscular septum and flexor-pronator aponeurosis. Due to the level of trapping in wrist, signs may be pure sensorial, pure motor or mixed. Guyon canal is one of the most common trapping region for ulnar nerve in wrist. The most important cause of trapping in Guyon canal is room occupying lesions. Diagnosis is made according to symptoms, physical examination findings or electrodiagnostic and radiologic studies. There are both conservative and surgical treatment options. Surgery is performed in patients if they do not respond to conservative treatment. All surgical treatment options give satisfying functional results for cubital tunnel syndrome. The results of trapping in wrist usually depends on its etiology. In this review; first the pathophysiological, clinical and electrophysiological diagnosis of ulnar nerve trapping, and then its surgical treatment options and results will be discussed.

Key words: ulnar nerve; entrapment neuropathy; cubital tunnel syndrome; decompression
U Inar sinir, anatomik yapısı nedeniyle, değişik nedenlerle hasara ve tuzaklanmaya uğrayabilmektedir. Ulnar sinirin dirsek bölgesindeki tuzaklanmaları; ulnar nöropati, tardy ulnar palsi, travmatik ulnar nöritis, ulnar sinirin kompresyon nöritisi, Feindel Osbom sendrom ve kübital tünel sendrom gibi değişik isimlerle tanımlanır.

Ulnar sinir, en sık lokal basıya ve travmaya en açık olduğu bölge olan dirsek bölgesinde tuzaklanır; ikinci sırada ise Guyon kanalı düzeyindeki tuzaklanmalar gelir.

Dirsek bölgesinde birçok potansiyel tuzaklanma bölgesi olmakla birlikte, dirsek düzeyindeki her tuzaklanma, yanlış bir alışkanlık olarak, kübital tünel sendromu olarak adlandırılabilir. Oysa, klinik ve elektrofizyolojik bulgular, basının yerine göre değişkenlik göstermektedir. El bileği hizasındaki ulnar sinir sıkışmaları (ulnar tünel sendromu), sıkışma seviyesine göre, saf motor,

- İletişim adresi: Dr. Mehmet Şükrü Şahin, Başkent Üniversitesi Tıp Fakültesi, Ortopedi ve Travmatoloji Anabilim Dalı, 07400 Antalya, Türkiye Tel: 0242 - 5112511 e-posta: msukrusahin@yahoo.com

- Geliș tarihi: 13 Ekim $2015 \quad$ Kabul tarihi: 13 Ekim 2015 


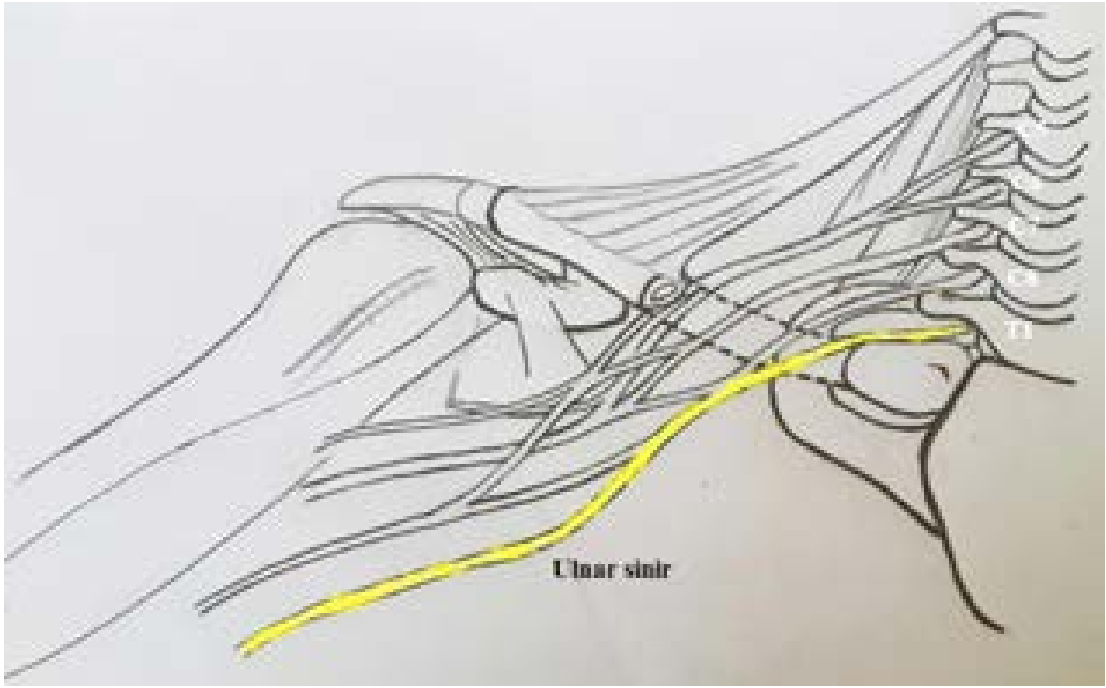

Şekil 1. N. Ulnaris, brakiyal pleksusun C7-C8-T1'den oluşan alt turunkusun mediyal kord liflerinden çıkmaktadır.

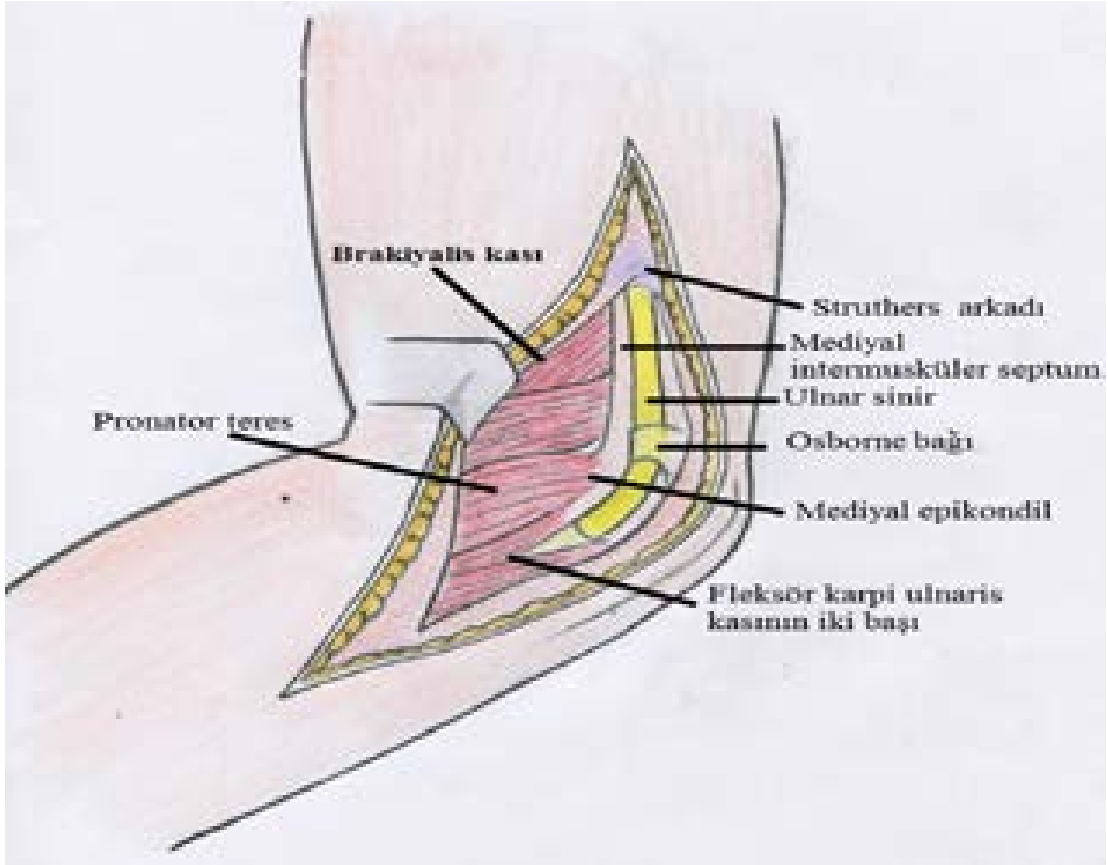

Şekil 2. Ulnar sinirin dirsek seviyesinde ilerlediği yol ve potansiyel tuzaklanma bölgeleri.

saf duyu ve mikst form olarak üç farklı tipe ayrılmıştır. Sıklıkla tanısı geciken bir durum olması nedeniyle, ulnar sinirin anatomisinin ve potansiyel tuzaklanma bölgelerinin bilinmesi, tanı ve tedavi yaklaşımları açısından oldukça önemlidir.

\section{ANATOMI}

Ulnar sinir, brakiyal pleksusun C7-C8-T1'den oluşan alt trunkus mediyal kord liflerinden çıkar. A. aksillarisin mediyal yüzünden sulkus bisipitalise girer ve mediyal epikondilin yaklaşık $10 \mathrm{~cm}$ proksimalinden mediyal intermusküler septumu delerek, ekstansör yüze döner. Mediyal epikondilin $8 \mathrm{~cm}$ proksimalinde, trisepsin mediyal başını intermusküler septuma bağlayan Struthers arkadının altından geçerek, dirsek seviyesinde mediyal epikondilin posteriorundan geçer (Şekil 1, 2).

N. ulnaris, mediyal epikondilin posterioruna geçince, lateralde Osborne bağı ve posteromediyalinde fleksör 


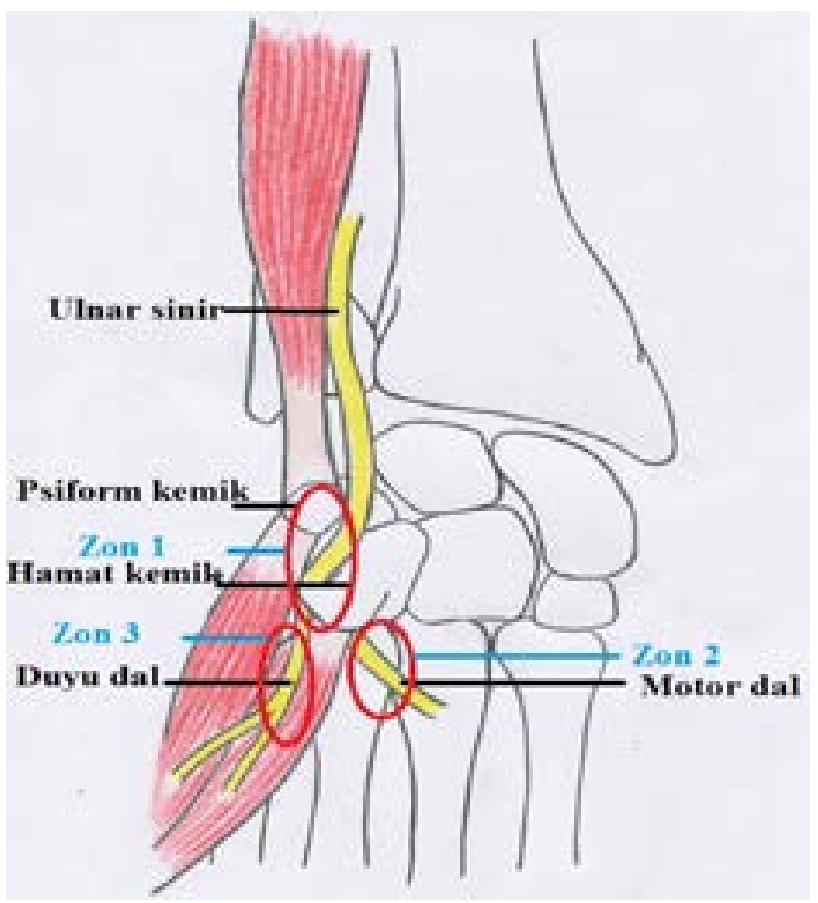

Şekil 3. Guyon kanalının yapısı ve muhtemel tuzaklanma bölgeleri.

karpi ulnaris (FKU) kasının başı tarafından sarılır. Bu iki yapı, kübital tüneli oluşturur. Kübital tünelin mediyal sınııını mediyale epikondil, lateral sınırını olekranon oluştururken; zemini dirsek kapsülü, çatısı da humeroulnar arkad (Osborne bağı) tarafindan yapılır (Şekil 2).

Ulnar sinir, kübital tünelden çıkınca FKU'nun iki başı arasında seyrederek, önkolun anterior kompartmanına girer. Bu sinir, kübital tünelden çııınca FKU'ya, mediyal epikondilin yaklaşı $5 \mathrm{~cm}$ distalinde de $\mathrm{m}$. fleksör dijitorum profundusun ulnar tarafına dallar verir. El bileğine gelmeden önce, dorsal ve palmar kutanöz dallarını verir.

Ulnar sinir, Guyon kanalında ulnar arter ile birlikte seyreder. Guyon kanalının uzunluğu yaklaşık $4 \mathrm{~cm}$ olup, transvers karpal bağın proksimal kenarı ile başlar, hipotenar arkın fibröz kısmıyla sonlanır. ${ }^{[1]}$ Radyal (mediyal) tarafını hamat kemiğin çengeli, ulnar (lateral) tarafını pisiform kemik, tabanını transvers karpal bağ, tavanını önkolun derin fasyasının devamı, volar karpal bağ oluşturur (Şekil 3).

Elin ulnar tarafindaki duyusunu almak için, palmar kutanöz dal, önkolun distalinde palmar tarafta seyreder ve el bileği hizasında Guyon kanalının üzerinden geçerek, elin palmar ulnar tarafında dağılır. Palmar kutanöz dalın birkaç santimetre proksimalinden, dorsal

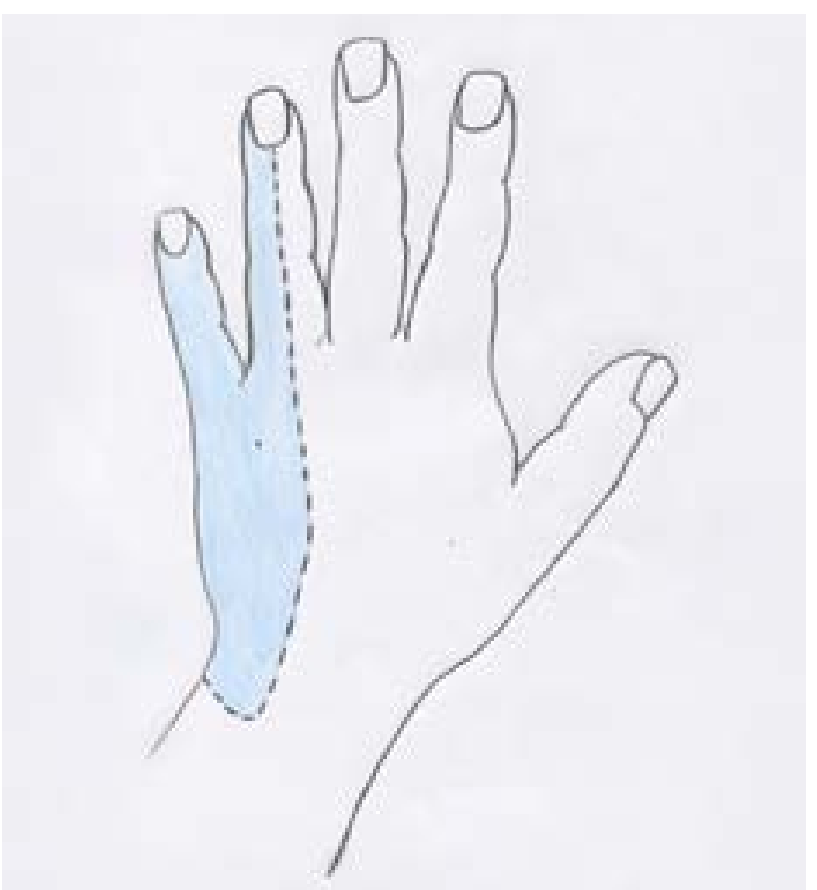

Şekil 4. Ulnar sinirin, elin dorsal yüzeyinde innerve ettiği duyu bölgesi.

kutanöz dal ayrılır ve elin dorsal ulnar tarafi, 5. parmağın dorsalinin ve 4. parmağın dorsal ulnar yarısının duyusunu alır (Şekil 4). Palmar ve dorsal kutanöz dallar, Guyon kanalının içinden geçmez.

Ulnar sinir, Guyon kanalını terk ettikten sonra, yüzeyel duyu ve derin terminal dallar olarak devam eder. Yüzeyel dal, elin ulnar palmar taraf duyusunu, 5. parmağın palmar tarafının ve 4. parmak palmar ulnar yarısının duyusunu alır (Şekil 5).

Derin terminal dal ise motor daldır ve elin küçük kaslarının neredeyse tümünü innerve eder. İnnerve ettiği kaslar; palmaris brevis, abduktor dijiti minimi, opponens dijiti minimi, fleksör dijiti minimi brevis, dorsal interossei, palmar interossei, 3. ve 4. lumbrikaller, adduktor pollisis ve fleksör pollisis brevisin derin başıdır.

\section{TUZAKLANMA BÖLGELERi}

Ulnar sinir, anatomik özellikleri nedeniyle en sık, lokal basıya ve travmaya en açık olduğu bölge olan dirsek bölgesinde basıya uğrar. ${ }^{[2]}$

Posner, dirsek bölgesinde beş potansiyel kompresyon alanı tanımlamıştır: ${ }^{[3]}$

1) Struthers arkadı,

2) mediyal intermusküler septum, 


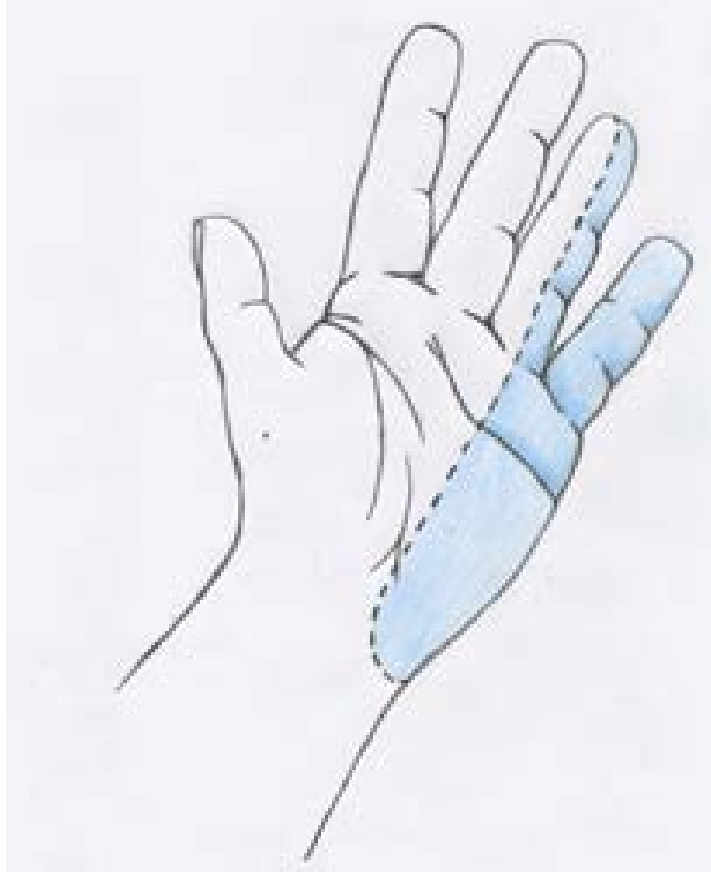

Şekil 5. Ulnar sinirin, elin volar yüzeyinde innerve ettiği duyu bölgesi.

3) kondiller-retroepikondiller oluk,

4) kübital tünel (humero ulnar arkad) ve

5) fleksör pronator aponöroz.

Ancak yanlış bir alışkanlık olarak, dirsek düzeyindeki her tuzaklanma, Freindel ve Stratford tarafindan tanımlanmış olan kübital tünel sendromu olarak ifade edilmektedir. ${ }^{[4]}$

En sık, kübital tünel ve retroepikondiller olukta tuzaklanma görülür. Guyon kanalı düzeyinde tuzaklanma, dirsek düzeyinden sonra ikinci en sık ulnar nöropatidir. Ulnar sinirin, Guyon kanalının proksimalinde veya distalinde basıya uğrayabildiği gibi, kanaldan çıktıktan hemen sonra avuç içinde de basıya uğrayabileceği unutulmamalıdır.

\section{ETIYOLOJi VE PATOFIZYOLOJi}

Yaşlanma ile, hem dirsekte hem de bilek düzeyinde ulnar nöropati görülme sıklığı artar. Dirsek düzeyinde ulnar nöropati, erkeklerde 3-8 kat daha fazla görülür. [5] Contreras ve arkadaşları, kadınlarda dirsek yağ dokusunun erkeklere göre 2-19 kat daha fazla olduğunu göstermiş, ayrıca erkeklerde coronoid tuberkülün 1,5 kat daha büyük olmasının, kompresyon riskini arttırdığını öne sürmüşlerdir. ${ }^{[6]}$
Vücut kitle indeksi (VKi) 22 ve altında olan kadınlarda, dirsek düzeyi ulnar nöropatinin daha fazla görüldüğü saptanmıştır. ${ }^{[5]}$ Ulnar sinir çevresindeki subkutanöz yağ dokusunun, kadınlarda akut ulnar nöropati için koruyucu olduğu belirtilmiştir. ${ }^{[5,6]}$ Ayrıca, erkeklerde dirsekte ulnar nöropatinin daha sık görülmesi, önkol kas kitlesi ve gücünün daha fazla olması ile açıklanamamaktadır.

En proksimaldeki kompresyon bölgesi olan Struthers arkadı, Kane ve arkadaşları ${ }^{[7]}$ tarafından tanımlanmıştır. Spinnerve Kaplan, özellikle suprakondiller humerus kırıklarından sonra ve anterior transpozisyon sonrası, Struthers arkadının ulnar sinir nöropatisine yol açabileceğini belirtmişlerdir. ${ }^{[8]}$ Dinamik hareketler sırasında, Struthers arkadı bir tuzak noktası gibi rol alıp miyelin kılıfta hasara yol açabilir. ${ }^{[9]}$

Geç ulnar palsi olarak da bilinen retrokondiller bası sendromunun etiyolojisinde, kondiller kırıklara bağlı valgus deformitesi, sinirin yineleyen subluksasyonu, artrit (sinovit, osteofit), travmatik hemoraji, yumuşak doku tümörleri (gangliyon, osteokondrom), dirseğin malpozisyonu yer almakla beraber, etiyoloji idiyopatik de olabilir.

Kübital tünel sendromu etiyolojisinde, fasyal bantlar, kubitus valgus, kitleler (lipom, gangliyon, osteofit), anormal yerleşimli kaslar, hipertrofik sinoviyum, ulnar sinir subluksasyonu, kalınlaşmış Osborne bağı, dirsek dayama alışkanlığı, tekrarlayan dirsek fleksiyonu sayılabileceği gibi, etiyoloji idiyopatik de olabilmektedir.

Ankoneus internus veya ankoneus epitrokleoolekrononis olarak da bilinen ankoneus epitroklearis kası, ilk defa Schafer ve arkadaşları tarafından tanımlanmıştır. ${ }^{[10]}$ Schaeffer tarafindan da, mediyal epikondil ve olekranon arasında uzanan aksesuvar bir kas olduğu belirtilmiştir. Bu kas, ulnar siniri kübital tünelde yüzeyel olarak çaprazladığı için, basıya neden olabilmektedir. ${ }^{[10]}$

Dirseğin tekrarlayan fleksiyon ekstansiyon hareketleri, dirsek düzeyindeki tuzaklanmaların önemli bir nedenini oluşturmaktadır. Dirsek hareket ederken, kübital tünelin şeklinin yuvarlaktan ovale döndüğü ve yüksekliğinin azaldığı, yapılan çalışmalarla gösterilmiştir. ${ }^{[11]}$ Bu yükseklik kaybı, kanal hacminin \%55 azalmasına ve kanal içi basınç artışına neden olur. Ekstansiyonda ulnar sinire ortalama $7 \mathrm{mmHg}$ olan basınç, dirsek fleksiyonu ile birlikte omuz ve dirsek pozisyonuna bağı olarak, 11-24 mmHg'ye ulaşır. Dirsek fleksiyonu ile birlikte FKU kontraksiyonunun, ulnar sinir üzerinde 20 mmHg'lik bir basınç yarattığı gösterilmiştir. Ayrıca ulnar sinir, dirsek rotasyon ekseninin arkasından geçtiğinden, dirsek fleksiyonu sırasında traksiyon 
ve ekskürsiyonda olur ve ortalama $5-8 \mathrm{~mm}$ uzar. ${ }^{[12]}$ Yapılan çalışmalarda, omuz abduksiyonu, dirsek fleksiyonu ve el bileği ekstansiyonu kombinasyonunun, kübital tünel basıncını altı kat arttırabildiği ve en yüksek basınç artışının bu pozisyonla olduğu bildirilmiştir. ${ }^{[12]}$ Ulnar sinir üzerindeki basıncı azaltmada ideal pozisyonun $45^{\circ}$ altında fleksiyon olduğu belirtilmekte ve bu nedenle, immobilizasyonun bu açıda yapılmasını öneren çalışmalar bulunmaktadır. ${ }^{[12]}$

Kubitus valgus deformitesinde dirsekteki valgus stresi sonucu, ulnar kollateral bağ ve ulnar sinirde traksiyon ortaya çıkmakta, bunun sonucunda sinirde inflamasyon meydana gelmekte ve sinir üzerine olan basınç artmaktadır. Murata ve arkadaşları, ulnar tünel sendromlu 31 olguluk serilerinde, hastalıkların \%45'inin idiyopatik, \%25,8'inin ise travma nedenli olduğunu bildirmişlerdir. ${ }^{[13]}$

El bileği seviyesindeki sıkışma, intrensek veya ekstrensik nedenlerden olabilir. Intrensek nedenler arasında en önemlisinin gangliyon kisti olmasıyla birlikte; nedenler, lipom, abduktor dijiti minimi kasının anormal pozisyonu veya fleksör karpi ulnaris tendonunun anatomik varyasyonu da olabilir. Ekstrensik nedenler arasında, yaralanmalar, pisiform veya hamat kemik kırıkları ve profesyonel veya aşıı kullanıma bağlı spor yaralanmaları sayılabilir. ${ }^{[14]}$

\section{KLINIK}

Ulnar sinirin farklı bölgelerde tuzaklanması sonucu ortaya çıkan semptomlar birbirlerine benzer. Hastalar, sıklıkla 5. parmak ve 4. parmak yarısında uyuşma ve paresteziden yakınırlar. Bunlara, el sıkma gücünde azalma, intrensek kas güçsüzlüğü ve el becerilerinde kayıp şeklinde bulgular eşlik edebilir.

Dirsek düzeyi ulnar nöropatilerde, bu semptomlara ek olarak, dirsekler üzerinde dururken veya dirsek fleksiyonu ile semptomlarda artma ortaya çıkar. Hastalar, dirsek düzeyinde, proksimale ve distale yayılabilen ağrı ve hassasiyet tanımlayabilirler. Semptomlar, künt bir rahatsızlık hissinden hiperesteziye kadar değişebilir. Ayrıca, dirsek fleksiyonu ile birlikte ortaya çıkan gece yakınmaları, ciddi derecede rahatsız edicidir.

Şiddetli ve uzun süreli olgularda, intrensek kaslarda güçsüzlüğe bağlı olarak pençe el deformitesi gelişebilir. İnterosseöz kasların paralizisi ile, uzun parmaklar metakarpofalangeal eklemlerden hiperekstansiyona gelir, interfalangeal eklemler hafif fleksiyon pozisyonunda kalır. Pençe el, ulnar sinirin el bileği ve altındaki her türlü lezyonunda oluşur. Bu deformite, median sinirin innerve ettiği I. ve II. lumbrikal kasların sağlam olması nedeniyle, 2. ve 3. parmaklarda çok hafif derecede oluşur.
İnterosseöz kaslar çalışmadığı için, uzun parmakların ekstansörleri ağır bastığından, 4 ve 5. parmak hafif abduksiyonda durur. Küçük parmakta pençeleşme ve abduksiyon ortaya çıkabilir (Wartenberg işareti). Başparmak, çoğu kez fleksör pollisis brevis kası paralizisi nedeniyle, metakarpofalengeal eklemden hiperekstansiyona gelir (Signe de Jeanne bulgusu).

Bu tipik duruş anomalisine ilaveten buna, 1. dorsal interosseöz kasında ve hipotenar kaslarda atrofi eşlik edebilir. Adduktor pollisis kasının paralizisi sonucu, başparmak adduksiyon yapılamaz. Başparmak ve işaret parmağı arasında bir kağıt tutulması istendiğinde, adduktorlar çalışmadığından, fleksör pollisis longus aktivitesi ön plana geçer ve başparmak interfalengeal eklemde fleksiyon yapar (Froment belirtisi).

Fizik muayenede, hassas bölgeler ve eklem hareket açıklıkları değerlendirilmeli, kitle lezyonu açısından palpasyon yapılmalıdır. İntrensek kasların kuvveti, el sıkma ve çimdik kuvveti, duyu alanı, vibrasyon duyusu, iki nokta duyarlılı̆ı ve deformitelerin varlığı değerlendirilmelidir. Lezyon yeri, dikkatli bir fizik muayene ile lokalize edilebilir.

Abduktor dijiti minimi, fleksör dijiti minimi (hipotenar kaslar), 1. dorsal interosseöz ve 2. palmar interosseöz kas güçleri değerlendirilmelidir. Abduktor dijiti minimi muayene edilirken, palmaris brevis kası da değerlendirilmelidir. Dorsal ve palmar kutanöz dalların duyu muayenesi yapılmalıdır.

Dirsek düzeyi tuzaklanmalarda, provokasyon testleri yapılmalıdır. Dirsek fleksiyon testi en tanısal olandır. ${ }^{[15]}$ Dirsekte $90^{\circ}$ yi geçen fleksiyon, önkola supinasyon ve el bileğine ekstansiyon yaptırılır. Parestezinin 60 sn'de ortaya çıkması veya artması durumunda pozitif kabul edilir. Omuz abduksiyonu da yapılırsa, testin tanısal kapasitesi artar.

Tinel işareti, dirsek bölgesine ulnar sinir trasesi boyunca vurulduğunda hassasiyet ve duyarlılık olmasıdır. Yapılan bir çalışmada, asemptomatik olguların üçte birinde Tinel işareti pozitif bulunmuştur. ${ }^{[16]} \mathrm{Bu}$ bulgu, Tinel işareti pozitifliğinin mutlaka diğer testlerle desteklenmesi gerekliliğini göstermektedir.

Ulnar sinir kompresyon testi; dirseğe 10 sn süre ile kompresyon uygulanması ile yapılır. Uyuşma ve parestezi gelişmesi durumunda, test pozitif kabul edilir.

Provokasyon testlerinin duyarlılığının incelendiği bir çalışmada, dirsek fleksiyon testi ve ulnar sinir kompresyonunun birlikte uygulanmasının en duyarlı provokasyon tekniği olduğu belirtilmiştir. ${ }^{[15]}$

Dirsek düzeyi ulnar sinir tuzak nöropatileri, fizik muayene bulguları esas alınarak yapılan McGowan sınıflamasına göre, hafif, orta ve şiddetli olarak evrelendirilir (Tablo 1). 
Tablo 1. McGowan sınıflaması

\begin{tabular}{lll}
\hline Evre $\mathbf{1}$ & Hafif & Ulnar sinir alanında parastezi, hipoestezi. Kaslarda güç kaybı yok. \\
\hline Evre 2 & Orta & Ulnar innervasyonlu kaslarda ılımlı güç kaybı. Minimal atrofi bulgusu var. \\
Evre 3 & Şiddetli & Ulnar innervasyonlu kaslarda belirgin atrofi. El intrensek kaslarda belirgin atrofi mevcut. \\
& & Pençe el olabilir/olmayabilir.
\end{tabular}

Ulnar sinir, el bileği hizasında derin ve yüzeyel dallara ayrıldığı için, ulnar sinir sıkışmaları semptomları, sadece motor (derin dal), sadece duyu (yüzeyel dal) veya mikst şeklinde olabilir. Parmak dorsallerindeki duyu kayıpları olmayabilir; çünkü, dorsal duyu dalı el bileğinin daha proksimalinden ayrılmaktadır.

Dört farklı lokalizasyonda sıkışma olabilir (Şekil 3): ${ }^{[14]}$

1) Guyon kanalının proksimalinde, psiform kemikte olur. Bu, yüzeyel ve derin dalın etkilenmesiyle, hem motor hem de duyuda defisite yol açar. Hipotenar ve elin intrensek kasları etkilenir (Zon 1).

2) Guyon kanalının içinde derin motor dalın sıkışmasıyla, sadece hipotenar ve elin intrensek kasları etkilenebilir. Duyu defisiti yoktur (Zon 2).

3) Guyon kanalının distalinde, hamat kemiğin çengeli hizasında olur. Aynı şekilde, derin motor dal etkilenir ve elin intrensek kaslarında güçsüzlük olur.

4) Palmaris brevis kası içinde, Guyon kanalı distalinde olur. Yüzeyel duyu dal etkilenir ve sadece duyu defisiti oluşur (Zon 3).

Ulnar tünelde sıkışmanın karakteristik fizik muayenesi yoktur. Eğer dirsekte kübital tünelde bir sıkışma yoksa, el bileği hizasında Tinel bulgusu pozitif olabilir. Kronik sıkışmalarda, elin intrensek kaslarında, FKU ve fleksör dijitorum profundus hariç, atrofi şeklinde kendini gösterir. Eğer bu sıkışma ulnar arter anevrizması ile birlikte ise, palpasyonla trill alınabilir. Ulnar arter trombüsü varsa, Allen testi pozitif bulunur. Hamatum çengelinde bir kırık ile birlikte ise, avuç içinde psiform kemiğin $1 \mathrm{~cm}$ distalinde ve radyalinde lokalize ağrı olabilir. Tanı koymak için, bilgisayarlı tomografi, anjiyografi ve manyetik rezonans görüntüleme kullanılabilir. ${ }^{[1]}$

\section{ELEKTRODIYAGNOSTIK INCELEMELER}

Tanıda klinik bulgu ve belirtiler esas olmakla birlikte, özellikle kompresyon bölgesinin lokalize edilmesinde, elektrodiyagnostik incelemeler önem taşır. Elektrodiyagnostik incelemelerin amacı, ulnar sinir hasarı olup olmadığının belirlenmesi, şiddetinin ortaya konması ve ayırıcı tanısıdır. Kompresyon bölgesine göre tedavi seçenekleri farklı olduğundan, bu ayrımın yapılması gereklidir.
Dirsek bölgesi ulnar nöropatinin elektrodiyagnostik tanısında en bilinen bulgu, ulnar sinir motor iletiminin dirsek segmentinde yavaşlamasıdır. Dirsek segment iletimi incelemesi sırasında, dirsek pozisyonu önemlidir. Dirsek ekstansiyonundayken, ulnar sinir gevşek, ölçülen yüzeyel mesafe gerçek sinir uzunluğundan kısadır. Bu nedenle, iletim daha yavaş bulunacağından, yalancı pozitif sonuç elde edilebilir. Aşırı fleksiyonda ise, ulnar sinirde dislokasyon oluşabileceği için iletim daha hızlı olacağından, yalancı negatif sonuç olabilir. Önerilen dirsek pozisyonu, $70-90^{\circ}$ fleksiyondur. ${ }^{[16]}$

Dirsek bölgesindeki ulnar nöropatinin tanısında, Amerikan Nöroloji Derneği'nin önerdiği kriterler kullanılmaktadır. ${ }^{[17]}$ Bunlar;

1) dirsek segmentinde ulnar sinir motor iletim hızının $50 \mathrm{~m} / \mathrm{sn}^{\prime}$ den daha düşük olması,

2) dirsek segmentinde ulnar sinir motor iletim hızının önkol segmentine göre $15 \mathrm{~m} / \mathrm{sn}$ daha düşük olması ve

3) dirsek üzerinden uyarımla elde edilen CMAP (Birleşik Kas Aksiyon Potansiyeli) amplitüdünün, dirsek altından uyarıma göre \%20'den fazla düşmesidir.

İki kriterin varlığı 'muhtemel', üç kriterin varlığı ise 'kesin' tanıyı koydurur.

\section{AYIRICI TANI}

Ayırıcı tanıda, brakiyal pleksus alt trunkus lezyonları, torasik çıkış sendromu, siringomiyeli, C8-T1 diskopati ve amiyotrofik lateral skleroz gibi hastalıklar düşünülmelidir. Servikal radikülopati gibi, sinire proksimalden kompresyon varlığı, sinirin distal segmentlerini kompresyon ve travmaya duyarlı hale getirir ve 'double crush' sendromu olarak adlandırılır.

\section{TEDAVi}

\section{Dirsek Düzeyinde Ulnar Nöropati}

\section{Konservatif Tedavi}

Kübital tünel sendromunda hasta eğitimi ve aktivite modifikasyonu, semptomları arttırıcı hareketlerin tekrarından kaçınılması açısından oldukça önemlidir. 


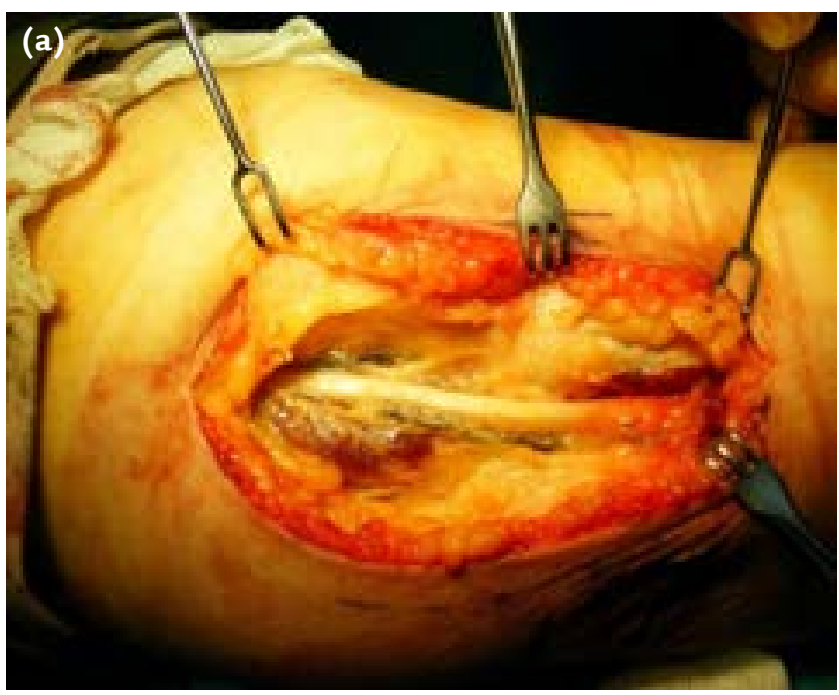

Şekil 6. a, b. Ulnar sinirin basit dekompresyonu.

Ilk dönemde amaç, ağrı, yüklenme ve inflamasyonun azaltılmasıdır.

Dirseği istirahate almak, inflamasyonu azaltıp semptomlarda azalma sağlar. Dirsek düzeyi ulnar nöropatisi olan hastalara, splint kullanımına ek olarak, lokal steroid enjeksiyonu uygulanmasının tedaviye ek yarar sağlamadığı belirtilmektedir.

Altı ila 12 haftalık konservatif tedaviye yanıt yoksa progresif paralizi, uzun süreli lezyon varlığını gösteren klinik kanıtlar eşlik ediyorsa (kas atrofisi, pençe el) cerrahi tedavi düşünülmelidir. Başarılı sonuç göstergesi olarak, cerrahi tedavi olmamanın alındığı bir izlem çalışmasında; dirsek düzeyi ulnar nöropati tanılı 128 hastanın 164 dirseği ortalama 58,6 ay takip edilmiş ve McGowan sınıflamasına göre, şiddetli düzeydeki hastaların \%62'si ameliyat olmuştur. ${ }^{[18]}$

Ulnar tünel sendromunun konservatif tedavisinde ise, şikayetin nedeni ve şiddeti oldukça önemlidir. Sıklıkla, dinlenmek ve neden olan gerginliğin azaltılması, şikayetlerin geçmesini sağlar. El bileği splintleri ve steroid enjeksiyonları denenebilir. Bisiklet yarışçıları çömelmiş pozisyonda ve elleri bisiklet barının altında kaldığı için, bu durum sıkışma semptomlarının artmasına neden olur; bu yüzden, ellerinin pozisyonlarını değiştirmeleri gerekir. Dövüş sporu ile uğraşan insanların avuçlarının ulnar taraflarına devamlı tekrar eden darbeler geldiği için, bu sporu yapanlarda sıkışma semptomları görülebilir. Bu tip hastalarda, steroid enjeksiyonu ve splintleme işe yaramaz.

Cerrahi tedavi yöntemi, lezyon yerine göre planlanır. Lezyon yeri, daha önce de belirtildiği gibi,

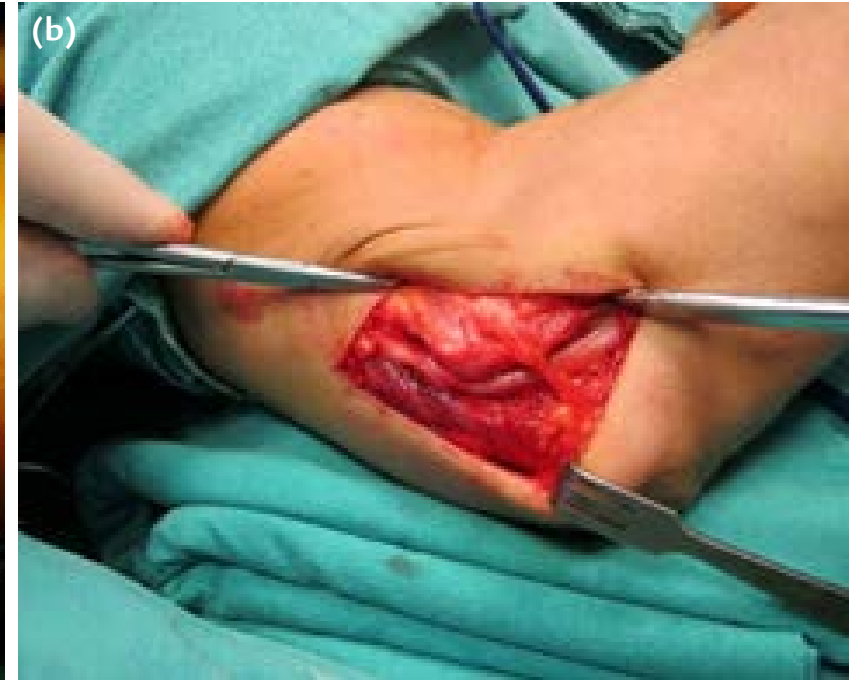

elektrodiyagnostik testlerle belirlenir ve böylece, cerrahi başarı büyük oranda artar. Humeroulnar arkad lezyonlarında in situ dekompresyon, retrokondiller oluk lezyonlarında ise anterior transpozisyon uygulanabilir. Ulnar sinirde subluksasyon, kaynamama, fraktür ve zayıf ulnar sinir yatağına bağlı durumlarda, mediyal epikondilektomi tekniğinin uygulandığı çalışmalar vardır. ${ }^{[19]}$ Ancak, hangi tekniğin en başarılı ve uygun teknik olduğuna dair literatürde tam bir görüş birliği yoktur.

Cerrahi işlemler kabaca iki grupta toplanabilir. Illki, sinirin transpozisyonuyla beraber (mediyal epikondilektomi dahil) dekompresyon, ikincisi ise transpozisyon yapılmayan (basit, in situ) dekompresyondur.

\section{Cerrahi Teknikler}

1. In situ dekompresyon: Ulnar sinirin basit dekompresyonu, retinakulum tarafından bölgesel basının sorumlu olduğu hipotezini temel almaktadır. Ulnar sinirin stabil olduğu, kübital oluk tabanının osteofit veya fraktüre bağlı anormal olmadığı olgularda, bu cerrahi yöntemi tercih edilmektedir. Hastalara, supin pozisyonda, dirsek fleksiyonda, kol abduksiyon ve dış rotasyonda olacak şekilde pozisyon verilir. Lokal ya da genel anestezi ile, mediyal epikondil proksimalinden başlayan, önkolda FKU'nun mediyal sınırına uzanan, yaklaşık 7-8 cm'lik insizyon yapılır. Ulnar sinir, seyri boyunca kübital olukta bası altında kaldığı bant ve bağlar açılarak, FKU kasına girdiği yere kadar dekomprese edilir (Şekil 6). Ulnar sinirde instabiliteye yol açmamak için, FKU kas bütünlüğünü bozacak kesme işleminden kaçınılır. 


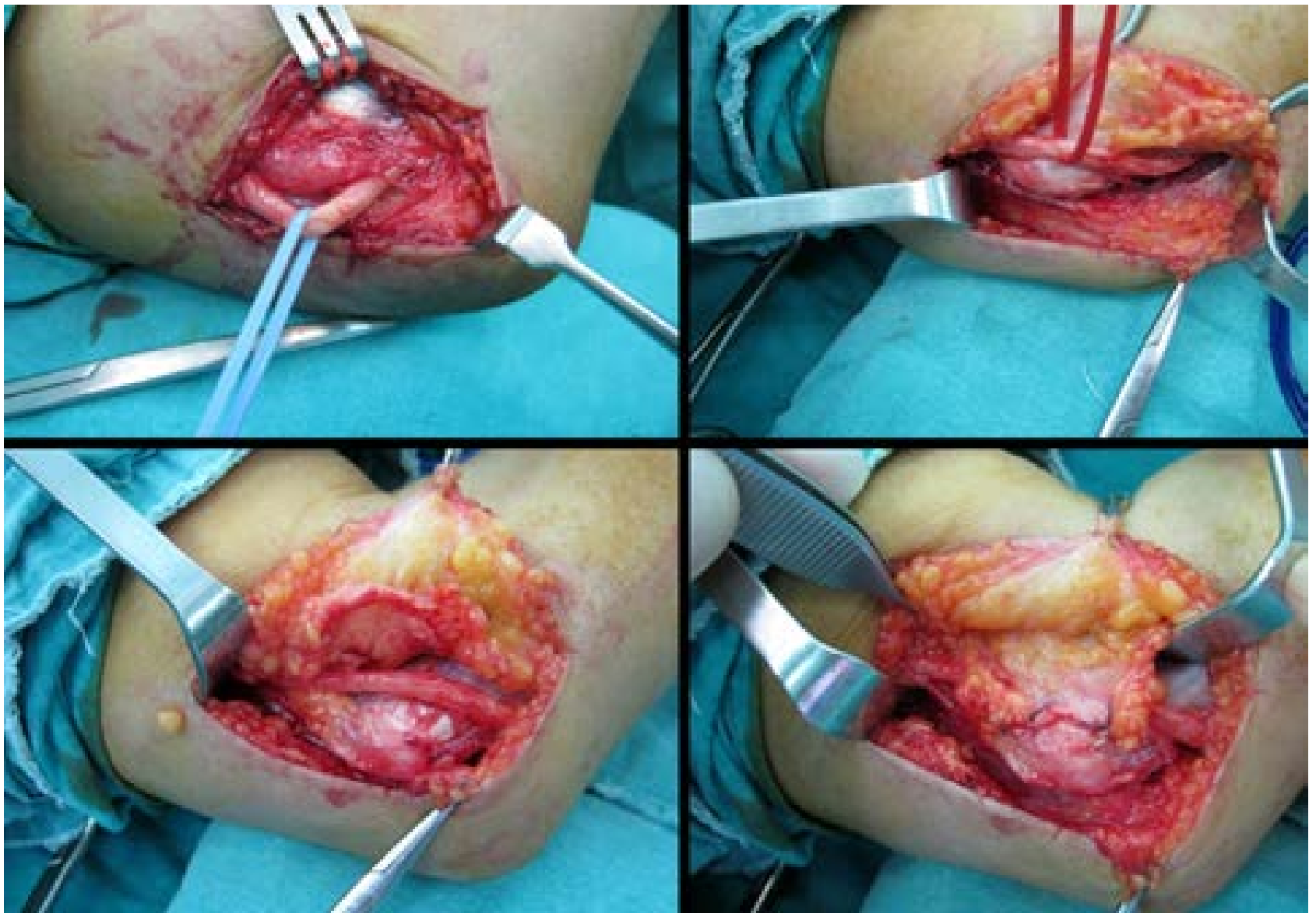

Şekil 7. Ulnar sinirin subkutan anterior transpozisyonu.

2. Anterior subkutan transpozisyon: Gerilme veya sürtünmenin sorumlu tutulduğu (valgus deformitesi), ulnar oluk tabanının anatomik yapısının bozulduğu (dirseğin osteoartriti) olgularda, bu yöntem tercih edilir. Transpoze edilen sinir daha hassas hale geleceğinden, çok zayıf kişilerde bu yöntem önerilmez. Hasta pozisyonu ve cilt insizyonu, in situ dekompresyon tekniğinde anlatıldığı şekilde yapılır. Ulnar oluk aponevrozu kesilerek, FKU kasına kadar sinir ortaya konulur ve proksimale doğru mobilize edilir. Struthers kemeri proksimalden serbestlenerek, mediyal intermusküler septumun distal 2-3 cm'lik kısmı eksize edilir. Distalde sinir, FKU kasına doğru takip edilerek, fasyal bant ve yapışıklıklardan temizlenir. FKU kası proksimali 1,5-2 cm eksize edilerek, dekompresyon distale uzatılır. Daha sonra sinir, subkutan alana transpoze edilerek, subkutan tabaka direkt olarak transpoze edilen sinirin mediyalinde, derin fasyaya sütüre edilir (Şekil 7).

in situ dekompresyon sınırlarını iyi belirlemek ve tuzaklanma ortadan kalktıktan sonra, dekompresyonu distal ve proksimale doğru gereksiz yere ilerletmemek gereklidir.

3. Intermusküler transpozisyon: Eğer ulnar sinirde instabilite gelişirse, pronator teres ve FKU kaslarını içeren, anterior intermusküler transpozisyon yöntemi uygulayarak (Şekil 8), sinirin önkol fleksiyon ve ekstansiyonu sırasında stabilitesini sağlamak önemli hale gelmektedir. ${ }^{[20]}$

4. Mediyal epikondilektomi: Kübital tünelin cerrahi tedavisinde başarı ile uygulanan bir yöntemdir. Bazı çalışmalarda, anterior transpozisyondan daha başarılı sonuçlar bildirilse de, genel olarak tüm cerrahi yöntemlerin tekniğine uygun yapıldığında, kabul edilebilir iyi sonuçlar verdiği yaygın olarak kabul görmektedir. ${ }^{[21]}$ Bu teknikte, mediyal epikondilden bir parça eksize edilerek, kararsız olan ulnar sinirdeki gerginlik ve bası ortadan kaldırılır (Şekil 9); ulnar sinirin kanlanmasının bozulmaması, önemli bir avantajdır.

Ulnar tünel sendromunun cerrahi tedavisinde ise, el bileği hizasından FKU ve fleksör tendonlar arasından 


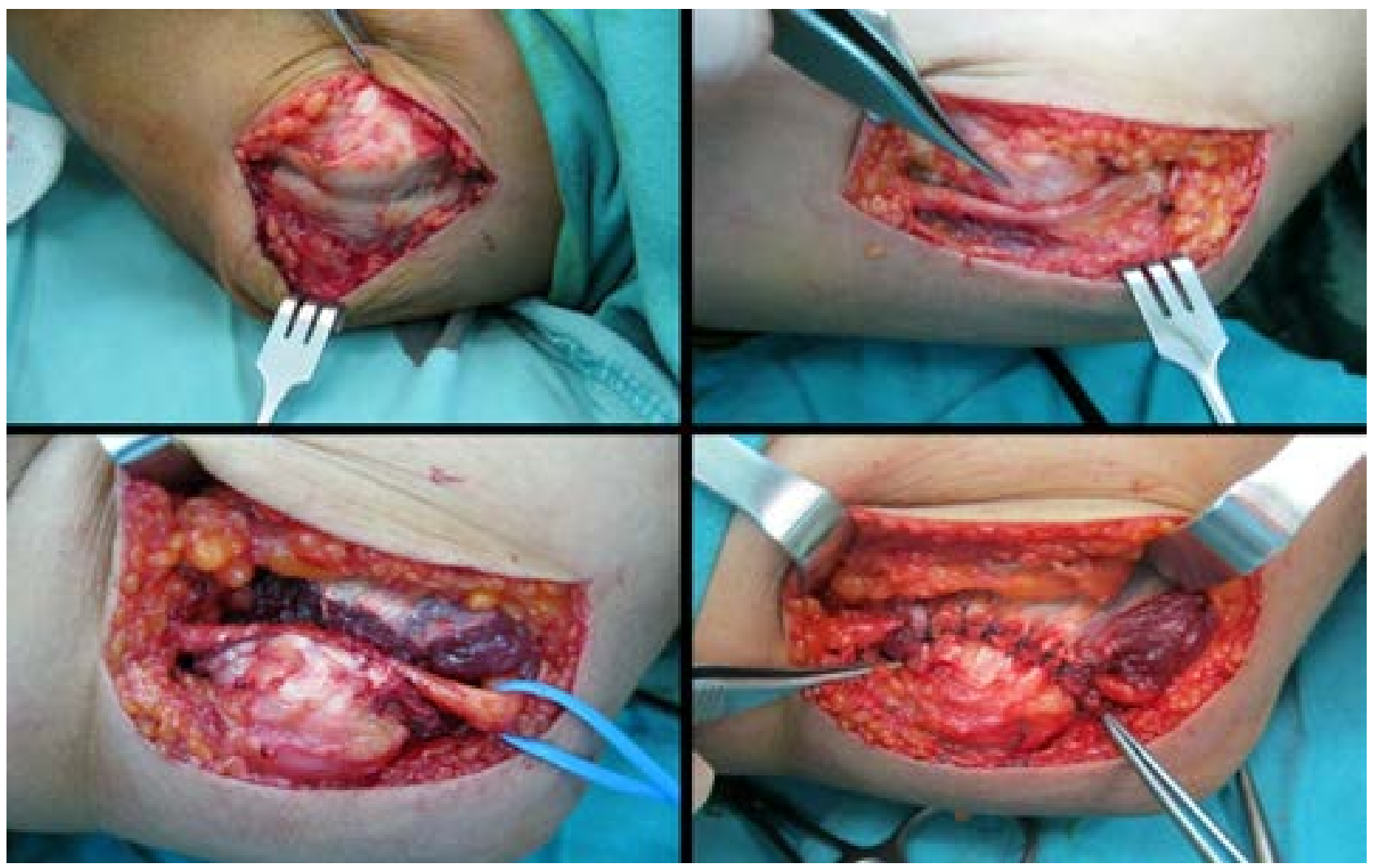

Şekil 8. Ulnar sinirin anterior intramusküler transpozisyonu.
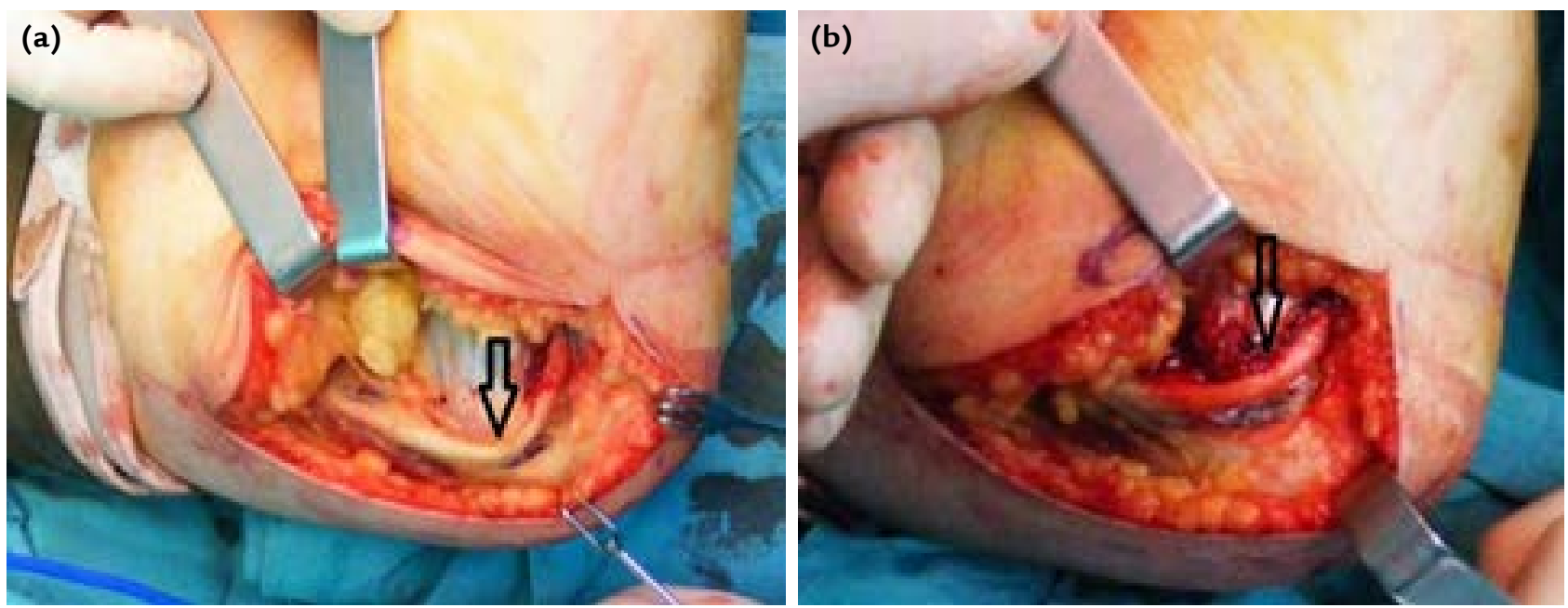

Şekil 9. a, b. Mediyal epikondilektomi öncesi ulnar sinir gergin görünümdeyken (a), mediyal epikondilektomi sonrası gerginlik ortadan kaybolmaktadır (b).

eğimli bir insizyonla, psiform ve hamat kemiğin arasından, el bileği çizgisi oblik şekilde geçilerek girilir (Şekil 10). Ulnar sinir distale doğru izlenir ve volar karpal bağ gevşetilir. Ulnar arter, anevrizma veya trombüs açısından izlenir. Hipotenar kasların fibröz arkı açılır ve kitle, fibröz bant veya anormal bir kas varsa, izlenir. Eldeki sıkışmalar için, derin motor dal takip edilir. Insizyon, adduktor pollisis kasına giren motor dala kadar genişletilir. Yer kaplayan lezyonların çıkarılması, hastaların büyük çoğunda klinik düzelme sağlamaktadır. Komplikasyonlar arasında ise, en çok ulnar sinir veya arter dallarının yaralanması sayılabilir. 


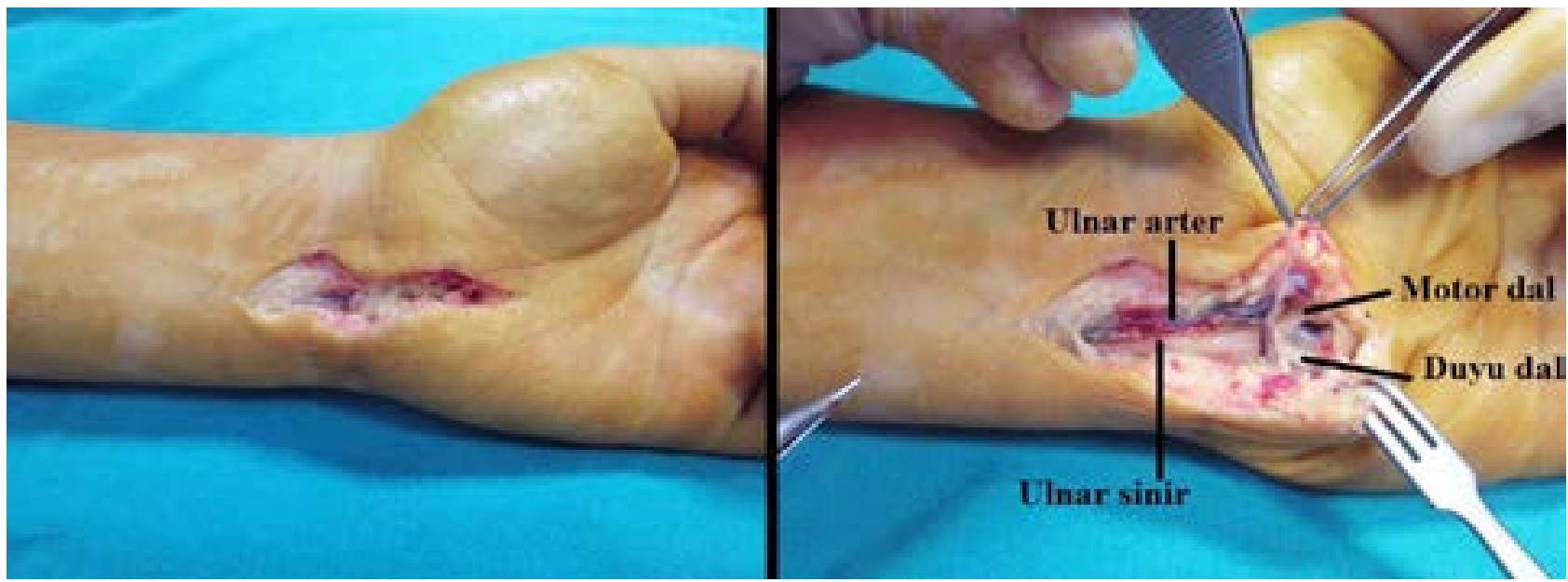

Şekil 10. Ulnar sinirin Guyon kanalındaki seyri ve cerrahi olarak dekompresyonu.

\section{TARTIŞMA}

Kübital tünel sendromu tedavisi ile ilgili klasik bilgiler, hastalara önce konservatif tedavi denenmesi ve eğer düzelmezse cerrahi tedaviye geçilmesi yönündedir.

Hangi cerrahi tedavi yöntemi uygulanırsa uygulansın, kübital tünel sendromu cerrahisinin fonksiyonel sonuçları, eğer tutulum çok ileri düzeyde değilse, genellikle olumludur. ${ }^{[22]}$

Basit dekompresyon, ulnar tuzak nöropatilerde en çok kullanılan cerrahi tekniktir. ${ }^{[23]}$ Ulnar sinir, kübital tünelin tavanını oluşturan aponevrotik fibrotik bir bant olan arkuat bağın kesilmesiyle dekomprese edilebilir. ${ }^{[24]}$ $\mathrm{Bu}$ yöntemin, nöropatinin hafif, kemik anatomisinin normal ve arkuat bağın sıkışmaya neden olduğu olgularda kullanılması daha uygundur. Basit dekompresyonun dezavantajının, tekrarlayan ulnar sinir tuzaklanması olabileceğini belirten yayınlar mevcuttur. ${ }^{[25]}$ Ayrıca, tekrarlayan ulnar sinir dislokasyonu da basit dekompresyonun en önemli dezavantajıdır.

Endoskopik ulnar sinir dekompresyonu, minimal invaziv bir tekniktir. Yara yeri iyileşmesinin hızlı olması, az skar dokusu gelişimi ve cerrahiye bağlı komplikasyonların nadir görülmesi, önemli avantajlarıdır. [26] Bununla birlikte, maliyetinin yüksek olması, yeterli klinik veri bulunmaması, sinir tuzaklanmasının ileri derecede olduğu olgularda ve obez hastalarda ulnar sinirin dekompresyonun yeterince sağlanamaması gibi, önemli zorlukları bulunmaktadır. ${ }^{[26]}$

Ulnar sinirin, antekübital fossa içine, cilt altına, kasın içine veya kasın altına anterior transpozisyonu da yaygın kullanılan bir cerrahi yöntemdir. Ancak, hangi hastaya hangi yöntemin seçileceği konusunda, literatürde tam bir fikir birliği yoktur. ${ }^{[27]}$
Literatürde, kübital tünel sendromu cerrahisi ile ilgili verilen fonksiyonel sonuçlar, genellikle iyi ve mükemmeldir. ${ }^{[27]}$ Ancak, dekompresyon veya transpozisyon işlemi sırasında, ulnar siniri besleyen kan akımının bozulabileceği, sinirde atrofi gelişebileceği, kesi etrafında duyu kusuru ve nörinom olabileceği de akılda tutulmalıdır. ${ }^{[22,28]}$

Bazı araştırmacılar, kadavra çalışmalarıyla, damarlanmasının bozulmaması için ulnar sinirin arterleriyle birlikte transfer edilebileceğini göstermişlerdir. Messina ve Messinaqa, anterior transpozisyon sinirin vasküler demetiyle beraber yapılırsa, ulnar sinirin beslenmesinin bozulmadığını ve iyileşmenin daha çabuk olduğunu belirtmişlerdir. ${ }^{[29]}$

Yamaguchi ve arkadaşları, 22 taze insan kadavrası üzerinde yaptıkları çalışmada, kanlanmaya en önemli katkının, alt ulnar kollateral arter tarafından sağlandığını belirtmişlerdir. ${ }^{[30]}$ Anterior transpozisyon sırasında, bu damarlar hasar görebilir ve sinir nispeten hipovasküler hale gelebilir.

Kübital tünel sendromununda, cerrahi tedavinin zamanlaması önem taşımaktadır. En az altı ay süren konservatif tedaviye yanıt yoksa veya kas atrofisi ya da pençe el gibi deformiteler gelişmiş ise, cerrahi geciktirilmemelidir. ${ }^{[27]}$

Sonuç olarak, kübital tünel sendromunun cerrahi tedavisi, konservatif tedaviye yanıt vermeyen hastalarda tatmin edici sonuçlar vermektedir. Cerrahi endikasyon konduktan sonra, ameliyat geciktirilmemelidir.

Fonksiyonel sonuçlar çok iyi olsa da, özellikle transpozisyon yapılan hastalarda, ulnar sinirin kanlanmasının bozulduğu ve kesi etrafında duyu kusuru kaldığı hatırda tutulmalıdır. Buradan yola çıkarak; eğer ek bir 
gereklilik yoksa, kübital tünel sendromu cerrahisinde sadece basit dekompresyon yapılması mantıksız olmayacaktır.

\section{TEŞEKKÜR}

Makale yazımındaki katkılarından dolayı Prof. Dr. Illhami Kuru'ya ve metin içerisindeki resimlerin çizimindeki katkılarından dolayı da Dr. Mustafa Çağrı Avcı'ya teşekkür ederiz.

\section{KAYNAKLAR}

1. Chung, KC. Techniques for nerve compression syndromes. In: Chung, KC, editor. Hand and Upper Extremity Reconstruction. USA: Saunders Elsevier; 2009.

2. Descatha A, Leclerc A, Chastang JF, Roquelaure Y; Study Group on Repetitive Work. Incidence of ulnar nerve entrapment at the elbow in repetitive work. Scand J Work Environ Health 2004;30(3):234-40.

3. Posner MA. Compressive neuropathies of the ulnar nerve at the elbow and wrist. Instr Course Lect 2000;49:305-17.

4. Feindel W, Stratford J. Cubital tunnel compression in tardy ulnar palsy. Can Med Assoc J 1958;78(5):351-3.

5. Richardson JK, Gren DF, Jamieson SC, Valentin FC. Gender, body mass and age as risk factors for ulnar mononeuropathy at the elbow. Muscle Nerve 2001;24(4):551-4.

6. Contreras MG, Warner MA, Charboneau WJ, Cahill DR. Anatomy of the ulnar nerve at the elbow: potential relationship of acute ulnar neuropathy to gender differences. Clin Anat 1998;11(6):372-8.

7. Kane E, Kaplan EB, Spinner M. Observations of the course of the ulnar nerve in the arm. Ann Chir 1973;27(5):487-96.

8. Spinner M, Kaplan EB. The relationship of the ulnar nerve to the medial intermuscular septum in the arm and its clinical significance. Hand 1976;8(3):239-42.

9. Ochiai N, Honmo J, Tsujino A, Nisiura Y. Electrodiagnosis in entrapment neuropathy by the arcade of Struthers. Clin Orthop Relat Res 2000;(378):129-35.

10. Schafer ES, Symington J, Brice TH. Quain's elements of anatomy, 11th ed. London: Longman Green and Co; 1923.

11. Tang DT, Barbour JR, Davidge KM, Yee A, Mackinnon SE. Nerve entrapment: update. Plast Reconstr Surg 2015;135(1):199e-215e. CrossRef

12. Bozentka DJ. Cubital tunnel syndrome pathophysiology. Clin Orthop Relat Res 1998;(351):90-4.

13. Murata K, Shih JT, Tsai TM. Causes of ulnar tunnel syndrome: a retrospective study of 31 subjects. J Hand Surg Am 2003;28(4):647-51.

14. Ombregt, L. Nerve lesions and entrapment neuropathies of the upper limb. In: A System of Orthopaedic Medicine. China: Elsevier; 2013. p.119-56.

15. Shah CM, Calfee RP, Gelberman RH, Goldfarb CA. Outcomes of rigid night splinting and activity modification in the treatment of cubital tunnel syndrome. J Hand Surg Am 2013;38(6):1125-30. CrossRef
16. Kuschner SH, Ebramzadeh E, Mitchell S. Evalution of elbow flexion and linel tests for cubital tunnel syndrome in asymptomatic individuals. Orthopedics 2006;29(4):305-8.

17. American Association of Electrodiagnostic Medicine, Campbell WW. Guidelines in electrodiagnostic medicine. Practice parameter for electrodiagnostic studies in ulnar neuropathy at the elbow. Muscle Nerve Suppl 1999;8: S171-205.

18. Dellon AL, Hament W, Gittelshon A. Nonoperative management of cubital tunnel syndrome: an 8-year prospective study. Neurology 1993;43(9):1673-7.

19. Osei DA, Padegimas EM, Calfee RP, Gelberman RH. Outcomes following modified oblique medial epicondylectomy for treatment of cubital tunnel syndrome. J Hand Surg Am 2013;38(2):336-43. CrossRef

20. Topuz A, Eroğlu A, Dinç C, Atabey C, Çolak A. İn-situ dekompresyona bağlı gelişmiş ulnar sinir instabilitesi: Olgu Sunumu. Türk Nöroşirürji Dergisi 2012;22:67-70.

21. Geutjens GG, Langstaff RJ, Smith NJ, Jefferson D, Howel CJ, Barton NJ. Medial epicondylectomy or ulnar-nerve transposition for ulnar neuropathy at the elbow? J Bone Joint Sur $\mathrm{Br}$ 1996;78(5):777-9.

22. Oskay D, Meriç A, Kirdi N, Firat T, Ayhan C, Leblebicioğlu G. Neurodynamic mobilization in the conservative treatment of cubital tunnel syndrome: long-term follow-up of 7 cases. J Manipulative Physiol Ther 2010;33(2):156-63. CrossRef

23. Burns PB, Kim HM, Gaston RG, Haase SC, Hammert WC, Lawton JN, Merrell GA, Nassab PF, Yang LJ, Chung KC. Predictors offunctional outcomes after simple decompression for ulnar neuropathy at the elbow: a multicenter study by the SUN study group. Arch Phys Med Rehabil 2014;95(4):680-5. CrossRef

24. Nabhan A, Ahlhelm F, Kelm J, Reith W, Schwerdtfeger K, Steudel WI. Simple decompression or subcutaneous anterior transposition of the ulnar nerve for cubital tunnel syndrome. $J$ Hand Surg Br 2005;30(5):521-4.

25. Collier A, Burge P. Management of mechanical neuropathy of the ulnar nerve et elbow. Current Orthopedics 2001;15:256-63.

26. Mirza A, Mirza JB, Lee BK, Adhya S, Litwa J, Lorenzana DJ. An anatomical basis for endoscopic cubital tunnel release and associated clinical outcomes. J Hand Surg Am 2014;39(7):1363-9. CrossRef

27. Bacle G, Marteau E, Freslon M, Desmoineaux P, Saint-Cast Y, Lancigu R, Kerjean Y, Vernet E, Fournier J, Corcia P, Le Nen $D$, Rabarin F, Laulan J. Cubital tunnel syndrome: comparative results of a multicenter study of 4 surgical techniques with a mean follow-up of 92 months. Orthop Traumatol Surg Res 2014;100(4 Suppl):S205-8. CrossRef

28. Cutts S. Cubital tunnel syndrome. Postgrad Med J 2007;83(975):28-31.

29. Messina A, Messina JC. Transposition of the ulnar nerve and its vascular bundle for the entrapment syndrome at the elbow. J Hand Surg Br 1995;20(5):638-48.

30. Yamaguchi K, Sweet FA, Bindra R, Gelberman RH. The extraneural and intraneural arterial anatomy of the ulnar nerve at the elbow. J Shoulder Elbow Surg 1999;8(1):17-21. 